\title{
Analysis on Pinduoduo Business Model and Future Development Strategy based on Sinking Market
}

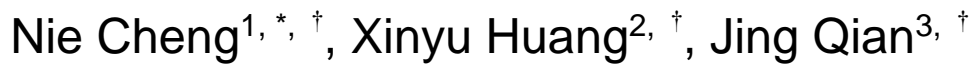 \\ ${ }^{1}$ Department of economics, South-Central University for Nationalities, Wuhan, China \\ 2 Department of economics and management, Bengbu University, Bengbu, China \\ ${ }^{3}$ Department of business administration, Changzhou Institute of Technology, Changzhou, China \\ ${ }^{*}$ Corresponding author: 201821065137@mail.scuec.edu.cn \\ These authors contributed equally
}

\begin{abstract}
This paper analyses Pinduoduo's success and make suggestions to help it further improve its business model for the long term and provide a reference experience of similar e-commerce companies by using moat theory. In the long run, the competitiveness of its competitors in the same industry cannot be underestimated. In the current situation, Pinduoduo's moat is weak in terms of intangible assets and user conversion costs due to the poor quality of most of the products on its platform and that its primary users are price-sensitive users. In this context, the authors give following suggestions for its future development: 1 . Highlight brand characteristics and ensure product quality 2. Create differentiated competitive advantages 3 . Improve supply chain structure and back-end service system 4 . Refined operation of existing users and stop blindly expand users.
\end{abstract}

Keywords: Business model analysis, case study, moat theory, Pinduoduo

\section{Introduction}

In recent years, mainstream e-commerce companies such as Tmall, Jingdong, and Suning have taken $90 \%$ of the market share in the e-commerce sector. The whole e-commerce industry is booming and has fierce competition. At this point, it is not easy for new entrants to gain a particular market share and overgrow, but Pinduoduo has done so. It has become the third-largest e-commerce platform in China by using its unique social e-commerce model and social platform's traffic like WeChat, targeting people with high price sensitivity. The rise of Pinduoduo is so fast that it is undoubtedly a dark horse among a host of small and middle e-commerce platforms, grabbing huge profits and attention from the traditional e-commerce giants such as Taobao and Jingdong in a competitive ecommerce battle. In summary, if companies do not want to be eliminated from the market, they must adopt a business model that suits them to create differentiation by winning attention and expanding the market scale and influence to achieve profitability in the competition eventually.

\section{Literature Review}

\subsection{Foreign Research Literature}

\subsubsection{Research on the definition of business model}

The term 'Business Model' was first considered by Timmers as 'a mathematical model based on a simulation procedure of business activities,' which can also be called 'the business model of an enterprise.' It is believed that the business model covers a vast and complex range. Timmers believes that a business model is an architecture that combines the flow of products, services, and information, the potential benefits of each player, and the sources of revenue [1]. In his 'The business model concept,' Thomas proposes that the definition of a business model should include processes, suppliers, customers, channels, resources, and capabilities. A business model is a general construct of the above elements that bring benefits to a company [2]. However, Zott and his partners argue that the business model explains value creation through a firm's transactional activities' structure, content, and process. 
Volume 16 (2021)

In contrast, from a process perspective, they see business models as the necessary resources and means to accomplish a range of business activities [3].

\subsubsection{Research on the elements of a business model}

Hamel believes that a business model should be practically meaningful and that its components should include core strategies, strategic resources, value networks, and customer interfaces [4]. However, Osterwalder argues that the business model consists of four core elements: the product, the customer interface, infrastructure management, and the financial situation. In addition to this, he also describes these four dimensions in detail, including nine sub-elements: the sub-elements of a product are value proposition, the sub-elements of customer interface are target customers, sales channels, and customer relationships, the sub-elements of infrastructure management include value allocation, core competencies and cooperation networks, and the sub-elements of financial status include cost and revenue structure [5].

\subsection{Domestic Research Literature}

\subsubsection{Research on the definition of business model}

Zhong Kongshen and Sun Xiaojing believe that business model emphases the integration of an enterprise's own resources and external resources, and is a way of conducting business [6]. Besides, Yuan Lei defines business model from a strategic perspective, and believes that business model is the logic of how an enterprise achieves value creation by integrating enterprise resources [7].

\subsubsection{Research on the elements of a business model}

According to Weng Junyi's 'Business model innovation,' a business model is logically composed of three parts: customer interface, internal structure, and partner interface, all of which are composed of four essential elements: value object, value content, value submission, and value recovery [8]. Yuan Lei proposed three criteria for classifying business models: intrinsic elements as the criteria, classification based on external environmental factors, and classification of intrinsic elements combined with the dual criteria of the external environment, which provides new ideas for the classification of business model elements [9]. However, Wei wei's team argue that a business model encompasses the subject, content, mode, and commodity pricing in business activities and is a transactional structure established between the stakeholders of business activities. The business model can be seen as consisting of six elements: positioning, essential resources, business system, enterprise value, free cash flow structure, and profitability model, and realizing enterprise value is its ultimate goal [10]. Wu and his team classified business models into six categories: free, platform, long-tail, systematic, non-binding, and secondary innovation [11]. Hu haibo also divided business models into six categories, namely $\mathrm{O} 2 \mathrm{O}$ business model, "tool + community + business" model, platform business model, long-tail business model, free business model, and cross-border competition business model [12].

According to a review of the relevant literature, most of the foreign literature is based on theoretical analysis, exploring the scope of the role of business models. At the same time, domestic scholars focus on classifying business models and studying the components of business models based on different classifications. Although many scholars have studied the definition of business models, they have not yet formed a unified conclusion. On the other hand, scholars have attached importance to several elements from varying degrees, such as value proposition, network, profitability, and internal structure, which can play a better role in interpreting an enterprise's business model. At the same time, linking the Internet and business model together has become a trend in the future study of business models.

In conclusion, this paper takes Pinduoduo as the research object and is based on Pinduoduo's business model in the markets of third and below-tier cities and rural areas. It analyses Pinduoduo's moat in today's competitive e-commerce market environment from Warren Buffett's moat theory and provides corresponding suggestions for its future development strategy. The study will help Pinduoduo improve its business model for long-term development and provide a reference experience 
Volume 16 (2021)

for similar e-commerce companies to help them innovate their business model paths in the same market.

\section{Data and Method}

\subsection{Data}

Founded in May 2019, Pinduoduo is an e-commerce shopping app established late compared to the traditional e-commerce giants Jingdong and Taobao. Relying on low prices, social networking, group joining, platform recommendation, reverse customization, etc., Pinduoduo went public only three years after its establishment, ranking among the top three e-commerce companies and becoming a representative of the new generation of operating models in the e-commerce field. According to the financial statements, Pinduoduo's 2020 GMV was 1,667.6 billion yuan, a year-on-year increase of $66 \%$ from 2019's 106.6 billion yuan. The number of active buyers on the platform reached 823.8 million, a net increase of 195.7 million over the same period last year. In July 2018, Pinduoduo was officially listed on the Nasdaq Stock Exchange in the United States, and its stock price closed at US\$26.7 on the first day of listing, an increase of nearly $41 \%$ from the opening price of US\$19.

Pinduoduo's development mainly goes through three stages: exploration period, growth period and high-speed development period.

Exploration period (October 2015 to December 2016): At this stage, Pinduoduo has spent a lot of energy on market development and business model verification. During the period, the number of users has grown slowly, and the growth rate of GMV has been low. This stage is the power-up phase of Pinduoduo. Through a series of internal rectification and external mergers, the image of a leading domestic social e-commerce brand has been initially established. After just one year, monthly GMV has surpassed Vipshop, becoming the third largest integrated e-commerce brand after Taobao and Jingdong.

Growth period (January 2017 to December 2017): The preliminary exploration of the market has been completed, and the business lines and operational end have gradually matured. After receiving financing from Tencent, WeChat brought a lot of traffic to Pinduoduo. In this stage, the overall preference of users' comments, damage and quality of items on pinduoduo platform were greatly improved. Meanwhile, the control of back-end supply chain also achieved initial results, and inventory management and delivery speed improved significantly. This stage is very important for Pinduoduo and directly pushes it to the forefront.

High-speed development period (after December 2017): In December 2017, under the dual influence of the gradual maturity of the business model and the start of mini program, Pinduoduo's "low price + sharing" strategy achieved great success, and the monthly active users of mini program exceeded one million in 2 months after its launch. Monthly GMV also increased from 4 billion in March 2017 to 10 billion by the end of the year. In this stage, Pinduoduo, through a large amount of marketing stimulation, achieved rapid growth in both the number of users and transaction volume, showing outstanding performance.

\subsection{Method}

This article uses the moat theory to analyze the current business model of Pinduoduo and proposes some suggestions for its future development strategies based on the analysis.

Warren Buffett first introduced the concept of 'moats' in a letter to shareholders in 1993: "Coke and Gillette razors have increased their global market share in recent years, and the power of their brands, the characteristics of their products, and their sales strength give them a tremendous competitive advantage, creating a moat around their financial fortress [13]. In his book Warren Buffett's Moat, Pat Dorsey summaries and analyses the theory of corporate moats and identifies four key factors that constitute a strong moat: unique intangible assets, customer switching costs, network effects of business models, and cost advantages [14]. 
Intangible asset moats include brands, patents, and government monopoly licenses. For ecommerce platforms, branding is more critical for building a moat of intangible assets. It mainly includes brand searchability and brand premiumization. Brand searchability is reflected in the fact that consumers repeatedly buy products from a brand because of the brand. Brand premium capability states consumers are willing to pay for high prices just for the brand.

Customer switching costs. The ability of a company to sell a product or service that is difficult for customers to part with creates a customer switching cost that gives the company pricing power. For e-commerce platform companies, customer switching costs depend on two main elements: price \& fungibility. Price, the cost of a user's transaction on the platform, includes both the direct cost of purchasing goods and indirect costs such as the time consumed by shopping. fungibility looks at the services offered by the platform company and whether any other competitors are also offering them a better experience and at a lower price.

Network effect of business models. In all business models, it is not a single individual studied, but the business relationships between multiple players. At least two types of users are aggregated for platform-based businesses, one on the supply side and one on the demand side. The platform aggregates and matches their demand and supply to facilitate transactions. The network effect consists of two main types: the first, the same-side effect, which is generated between the same types of users. The second, the cross-border effect, is the effect between one user and another type of user.

Cost advantages. Some firms have a cost advantage through processes, geographical location, the scale of operation, or unique assets, which allows them to sell their products or services at a lower price than their competitors, thus giving them a significant competitive advantage.

\section{Results and Discussion}

\subsection{Macro Environment Analysis}

With the steady rise of The Disposable Personal Income in China over the last decade, the ecommerce industry in China has been developing in full flourish due to residents' growing consumption intention and the support of the relevant national e-commerce policy. Accompanied by the rapid-rising online retail penetration rate, the major e-commerce competition is also increasingly fierce. Competition between Taobao and Jingdong on the first and second tier-cities has been heating up. In comparison, the battle between e-commerce firms did not spread to third and below tier-cities and rural areas smoothly where infrastructure is lacking, and transportation wastes too much time. Meanwhile, the specific marketing environment is not suitable for enterprises to use traditional operation mode to develop. At the same time, as consumption upgrades, mainstream e-commerce enterprises reduced competitiveness in the market of third and below-tier cities and rural areas because of higher commodity prices, like Jingdong abandoned 'Paipai', which is a business targeted to low-cost consumers [15].

However, judging from China's overall economic strength and people's consumption capacity, plenty of low-and middle-income people's consumption capacity has not been upgraded. Instead, They can not afford the price and pressure of housing and medical care and even chase goods with the same quality but low price. As a result, third and below tier-cities and rural markets dominated by consumers seeking the best value have a broad market demand. They could be a new blue sea after professional marketing exploration and guidance. According to Clayton Christensen's 'The Innovator's Dilemma: When New Technologies Cause Great Firms To Fail', Disruptive Innovation Theory states that extra technology supplies in the process of development force ordinary customers to pay higher prices for products [16]. However, low-end disruptive innovators focus on that unmet need to fill the blank with more straightforward and cheaper technologies. Fig. 1 presents Pinduoduo is sparked by Disruptive Innovation Theory, so it chose third and below tier-cities and rural areas as its target market, improving the corresponding infrastructure which e-commerce needs such as logistics system. At the same time, Pinduoduo seizes the critical point of consumer demand, focus on low price but better value goods. Meanwhile, it takes advantage of social media in the target market 
and quickly occupies the market through such measures as offering discounts if customers share links or invite others to purchase together, gradually success from rural areas and penetration of urban areas.

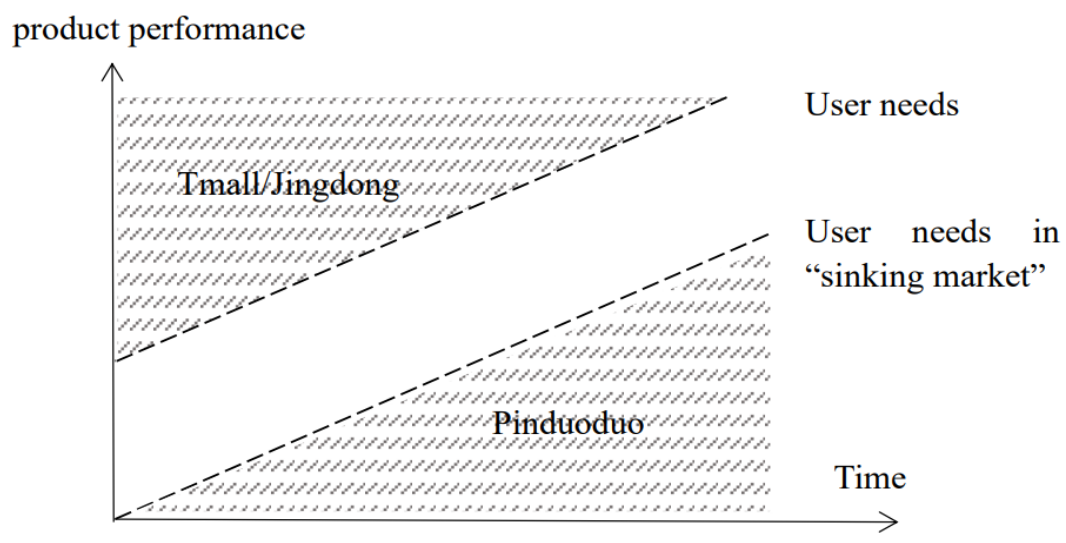

Fig. 1. The disruptive innovation of Pinduoduo.

On the flip side, Pinduoduo once can not provide lower price, or products they offer do not meet customers' expectations, user loyalty will be greatly reduced, so bargaining power of buyers is strong. Although Pinduoduo's suppliers are hardly able to compete with the platform and its new entrants and potential competitors pose less of a threat, more strong competitors will be a real threat to Pinduoduo in the long run. Jingdong developed a whole new app 'Jingxi', which targets low-and middle-income customers. Alibaba integrated 3 features to provide low-cost functions and discounts, launching in March 2020 Taobao special version and fully play Taobao's mature technology and market advantages. At the same time, Taobao requires resident merchants not to open other shops in Pinduoduo, forcing brands to choose one platform over the other. However, Pingduoudo's customers also use these similar apps. If merchants are forced to set up shops in e-commerce giants like Taobao due to the pressure and regulations, the influence of Pinduoduo will be reduced. So that competitors of Pinduoduo are a force to be reckoned with [17].

\subsection{Business Distress}

Pinduoduo now has 850 million users, and its user base has almost reached its peak. Although Pinduoduo tried to develop more features to attract new customers, such as 'duoduomaicai', an online grocery feature, these features' influence has been waning after a brief period of revenue and new users. On the other hand, Pinduoduo's innovation model can easily be copied by other competitors. As it turns out, Pinduoduo has used social platforms to attract more customers and get profit successfully, so that many e-commerce giants have followed suit and launch a similar model to split off some of Pinduoduo's target users. For example, Taobao for Pinduoduo of various types of game programs, the new launch of the "Baba Farm", Jingdong has also launched the corresponding 'Super million subsidies '.

In the wake of the continuous development of the economy and technology, customers' preference, which Pinduoduo targets, has changed slowly. People are no longer blindly pursuing low-priced products but in the search for low-priced but good quality goods. However, Pinduoduo's current strategy of low prices to attract customers is at odds with the target customer's future preference shift. Moreover, to make matters worse, drawbacks exposed by the extremely low-price strategy, such as fake goods, poor quality, and so on, all affect the enterprise's reputation. If this goes on, Pinduoduo will fall into the dilemma of being unable to transform because its target customers can only be limited to low-income people. The growth of the number of users is weak and its revenue. At the same time, the needs of the user group will gradually change [18]. None of the current shopping apps is irreplaceable such as Taobao, Tmall and Jingdong. If Pinduoduo's platform can not meet users' needs, users will be selected and migrated to other e-commerce platforms. Currently, Pinduoduo's target 
Volume 16 (2021)

customers are moving up the market due to the current strategy of meager prices does not fully meet the purchase needs of high-and middle-income groups.

\subsection{Mechanism Analysis}

In the face of competitors like Jingdong and Alibaba continue to penetrate the rural market, Pinduoduo's pressure is also increasing. Not only Pinduoduo needs to transform and upgrade the whole brand, facing the two-choice marketing dilemma of competitors coming to bring, but also to deal with the problem of slowing user growth. The following is based on Buffett's moat theory to analyze Pingduoudo's current situation and cope with the moat's corresponding challenges, thus providing appropriate recommendations for the future development strategy.

Intangible assets

It is clear that Pinduoduo does not have a wide moat of intangible assets to withstand strong competitors. Initially, in order to rapidly boost the number of users, Pinduoduo had to lower entry fees to the platform, using extremely low-costs operation to attract merchants from different categories to the platform. Although the extremely low-price strategy for both customers and merchants has helped Pinduoduo gain huge attention and transaction volume in a short period of time, the extremely low entry fees and overly simple product screening have allowed some unscrupulous merchants to use the platform to sell low quality goods. The intention of Pinduoduo is to be a platform that gathers low cost but high quality products at good value, but the lack of consistency with the philosophy of some irresponsible merchants has led to problems with the credibility of the platform. Thus customers will be hesitant to spend on a platform that does not guarantee the quality of the goods[19]. According to the Chinese Ministry of Commerce, trust in the platform and reliable delivery methods have become key advantages for major e-commerce companies to capture market share.

Compared to its main competitors Taobao and Jingdong, the brand image of Pinduoduo is mostly associated with low-priced and inferior products, and consumers have less trust in this platform. In terms of search ability, most users make fewer purchases on the Pinduoduo platform, resulting in a lower user repurchase rate compared to Taobao. In terms of price premium, even though its competitor, Jingdong APP, sells similar products at a higher price than Jindo, a significant proportion of users would still choose to buy from Jingdong rather than Pinduoduo because users think Jingdong has better brand reputation. As a result, the intangible asset moat of Jindo is narrow and shallow, while its competitors such as Jingdong and Taobao have deep and wide intangible asset moats.

Customer switching costs

There is no doubt that Pinduoduo, in the face of its rival giant Alibaba, still do not have the pricing power to bring profits [20].In terms of price, Pinduoduo's current low-cost strategy has attracted many users who are sensitive to price. Once the low-price advantage of the company's products is no longer available, the loyalty of its users will be reduced accordingly. In terms of alternatives, Pinduoduo's platform services are being copied by other competitors, and its former advantages are being lost. For example, at present, ByteDance is actively preparing the e-commerce competition. Once ByteDance, which controls the vast Internet traffic, enters the arena, the future competition of Pinduoduo will be more intense. Therefore, in terms of user switching costs, Pinduoduo has not formed a moat yet.

Network effects of business models

By take advantage of the cross-border effect, and the social fission path and the means, Pinduoduo takes WeChat to be the social platform, realizes the user fission through the game marketing and accumulates nearly 300 million traffic to let users know that the platform has an ample supply of high-value goods [21]. Meanwhile, manufacturers are also willing to set up shop here because the platform can gather a large number of customers; thus, its market expansion speed is breakneck, beside the network effect assumes the spiral rise. In terms of network effects, Pinduoduo has a deep and wide moat.

Cost Advantage 
So as to attract users, Pinduoduo mainly uses two methods: in the form of low-cost purchase and social fission marketing model. Pinduoduo aimed at price-sensitive users, providing lower prices to attract users to enhance the grasp of their consumer psychology. Besides, the explicit intuitive lowprice subsidies and discounts in the purchase pages stimulate consumer desire to buy. At the same time, the combination of social and e-commerce model to encourage consumers actively sharing links and invite friends to shop together for lower discounts, achieve free publicity among users and attract more user groups, and finally promote sales transformation.

In order to attract merchants, the strategy of Pinduoduo mainly includes reducing the cost of the supply chain and collecting consumer demand to give small and medium-sized merchants platform resources. On the one hand, Pinduoduo reduces the fees to entry and launch of the platform, and merchants do not pay the deposit in advance. So, the Merchant can reduce the goods price to chase more sales in Pinduoduo. On the other hand, in 2015-2016, when Pinduoduo was established, the ecommerce sector began to advocate 'Consumption upgrading'. Some small and medium-sized businesses are being squeezed out and removed during this fierce e-commerce battle. However, Pinduoduo gave them a chance to become the top of the line in this new platform. Table I shows the comparison of $\mathrm{C} 2 \mathrm{M}$ and $\mathrm{B} 2 \mathrm{C}$ mode, different from the general $\mathrm{B} 2 \mathrm{C}$ e-commerce, Pinduoduo is a $\mathrm{C} 2 \mathrm{M}$ model, Which means Pinduoduo could provide orders to partner factories according to user needs, and then manufacturers can always produce goods customers want. This efficient supply chain can guide the upstream supply chain to achieve a certain degree of mass customization, continue to produce widespread goods. Besides, there is no distribution, inventory and other intermediate steps in the whole circulation process, providing the platform for long-term sustainable cost advantage [22]. Therefore, Pinduoduo unique conditions for its cost advantage to building a solid moat.

TABLE 1. COMPARISON OF C2M MODE AND B2C MODE

\begin{tabular}{|c|c|c|}
\hline Process & $\mathrm{B} 2 \mathrm{C}$ & $\mathrm{C} 2 \mathrm{M}$ \\
\hline Production\&Sales & Produce before sales & Sell first and then produce \\
\hline Design & Homogeneous design & Personalized design \\
\hline Stock & High & Low \\
\hline Channel & $\begin{array}{l}\text { More processes and higher } \\
\text { prices }\end{array}$ & $\begin{array}{l}\text { Consumers directly dock with } \\
\text { the factory }\end{array}$ \\
\hline Cost & $\begin{array}{l}\text { High overall cost and low profit } \\
\text { margin }\end{array}$ & $\begin{array}{l}\text { Low overall cost and high profit } \\
\text { margin }\end{array}$ \\
\hline User & $\begin{array}{l}\text { Low user stickiness and high } \\
\text { maintenance cost }\end{array}$ & $\begin{array}{l}\text { High user stickiness and low } \\
\text { maintenance cost }\end{array}$ \\
\hline
\end{tabular}

In brief, Pingduoudo's moat is weaker in terms of intangible asset and user switching costs, but stronger in terms of network effects and cost advantages.

\section{Conclusion}

In summary, Pinduoduo takes advantage of its unique social e-commerce model to open up its own e-commerce field in the fiercely competitive Chinese e-commerce market with the sinking market as the starting-point. Due to the poor commodity quality, low price and most of the users are pricesensitive in the sinking market, the moat in intangible assets and customer swiching cost is weak. In comparison, it cooperates with WeChat APP and make use of its huge traffic, at the same time, the "social fission" approach to platform promotion and the adoption of the $\mathrm{C} 2 \mathrm{M}$ sales model to operate the platform has made it possible for the company to use its unique social e-commerce model to create its blue ocean of e-commerce. Against this background, Pinduoduo has a deep and wide moat in network effect and cost advantage.

Based on the above analysis of the current market environment and the moat theory, we propose the following strategies for the future development of Pinduoduo: 
Highlighting brand characteristics and to ensure product quality and strengthening the moat of intangible assets. In order to transform and upgrade under the attack of competitors, it is necessary to focus on its "billions subsidy" strategy to break people's inherent impression of "low price and poor quality" and improve the quality of products. The billions subsidy can be analyzed from two dimensions: consumers and merchants. The products that enter the billions subsidy program are highend brands, which can attract a wave of new customers in the middle and high end and use the subsidy to buy goods at a slightly lower price. These goods are inevitably cooperating with merchants and do not reach the bottom price, so Pinduoduo can still reap some revenue. This approach expands Pinduoduo's customer base to the high-end class. It allows Pinduoduo to have more sales and profitability, thus on the supply side, making the elemental plate of mid-to-high-end brands more prominent. The quality of platform goods and the amount of user consumption then gradually improved. Pinduoudo can also seize the opportunity to upgrade the growth of existing user consumption and gradually strengthen the moat in terms of intangible assets.

Create differentiated competitive advantages and build a wide moat of customer swiching costs. To firmly take the development of agriculture as the core strategy, Pinduoduo has been carrying previously out the action of helping farmers alleviate poverty by jointing social forces together and open sharing to help farmers and pave the way for the growth of new farmers in advance. At the same time, Pinduoduo has joined forces with the government and the media to carry out live streaming of agricultural products to sell products on the one hand and train new farmers. Now, Pinduoduo is the largest agricultural products platform in China. At the end of 2019, Pinduouduo had nearly 590,000 active merchants for agricultural products and more than 12 million directly connected farmers. With the implementation of this core strategy, Pinduoduo will deepen its moat to consolidate its position and realize its corporate social responsibility by helping farmers and rely on agriculture to build a differentiation advantage different from other platforms.

Improving the supply chain structure and the back-end service system, increasing the supply voice. Although Pinduoduo's existing supply chain structure has made it possible for customers' demand to stimulate the upstream supply chain to carry out mass production, its accumulation is still not perfect. Besides, the existing investment in the upstream and the empowerment of the whole industry chain are also insufficient. The existing investment in upstream and empowerment of the whole industry chain is also insufficient. If it wants to grow further, Pinduouduo will need to spend some time and effort on improving its supply chain. In addition to partnering with third-party logistics, it could follow the example of the Yiatong 380 platform and set up hundreds of distribution networks across the country. Otherwise, learning from Alibaba's retail and village tao synergy system and the integrated logistics information management platform of Cainiao parcel even benchmark itself against Jingdong and create its own logistics system to have a more significant say in the upstream supply.

Stop blind expansion of incremental users, fine-tuned operation of stock users. The Internet began to shift from a total market to a stock market as early as 2016, but the tapping of sinking traffic has slowed down the process. As the number of Pinduoduo 's users has reached 800 million, its future development strategy should no longer be to pursue incremental users number but to amplify the business value of individual users. Thus, it can refine the operation of its stock of users to repeat key actions through precise matching, increasing their stickiness and keeping them in a mature stage for a long time.

Although Pinduoduo's current single-user purchase level is still low, it also has the potential to improve within the system through live streaming, subsidies, and other actions to improve user stickiness. As its digital, household appliances, and fresh produce categories continue to enrich, the trend of increasing customer unit price is noticeable. Suppose it can maintain the existing scale and development direction. In that case, Pinduoduo in GMV s has more room for growth to better cope with the Tao system and other Internet e-commerce. It will allow Pinduoduo to better cope with the competition between the Tao system and other internet e-commerce companies and continue growing and developing. 


\section{References}

[1] Timmers, P., \& Iii, D. Focus Theme Business Models for Electronic Markets.

[2] Hedman, J., \& Kalling, T. The business model concept: theoretical underpinnings and empirical illustrations.

[3] Zott, C., Amit, R., \& Massa, L. (2010). The business model: theoretical roots, recent developments, and future research. Iese Research Papers, 37(4), 1019-1042.

[4] Hamel, G. (2001). Leading the revolution: Strategy \& Leadership.

[5] Casadesus-Masanell, R., \& Ricart, J. E.. (2010). From strategy to business models and onto tactics. Long Range Planning, 43(2-3), 195-215.

[6] Zhong genshen, \& Sun Xiaojing. (2006). Six perspectives and integration of business model research. Dongyue's Treatise, 27(002), 120-124.

[7] Yuan Lei. (2007). Reconstruction of business model system. Chinese industrial economy (06), 70-79.

[8] Weng junyi. (2004). Business model innovation. Economic Management Publishing House.

[9] Yuan Lei. (2008). Research on business model classification. Chinese soft science.

[10] Wei wei, Zhu Wuxiang, \& Lin Guiping. (2012). Business model theory based on stakeholder transaction structure. management world, 000(012), 125-131.

[11] Yao Mingming, Wu Xiaobo, Shi Yongjiang, Rong Ke, \& Lei Linan. (2014). Matching business model design and technology innovation strategy from the perspective of technology catch-up: A multi-case study. management world, 000(010), 149-162.

[12] Hu haibo. (2015). E-commerce business model innovation under the "Internet +" environment. Corporate research, 000(005), 21-23.

[13] Verburg, \& Peter. (2004). Belly up to the buffett buffet. Canadian Business, 77(10), 33-33.

[14] Tan Mengtong. (2018). Buffett's Moat: Finding a moat for investment funds. Investment and Finance, $000(002), 40-40$.

[15] Cao Zheng, Li Runfa, \& LAN Xue. Consumption driving and development strategy of e-commerce giants sinking market -- A Case study of Alibaba, JINGdong and Pinduoduo. Research on Business Economics (8), 3 .

[16] Christensen, C. M. The Innovator's Dilemma. Harvard Business School Press.

[17] Jin Zhiyong. (2020). Research on Pinduoduo enterprise Strategy from the perspective of innovation. Graduate School of Chinese Academy of Social Sciences.

[18] Fang Wen. (2019). Pinduoduo in painful transformation. Corporate Observer, 000(002), 76-78.

[19] Wang Jie. (2019). Analysis of pinduoduo development status and future prospects. Marketing (19), 25+27.

[20] Cui Guilin (2020-05-18). The moat of Pinduoduo. Economic Observer,020.

[21] Chen Weiru, \& Yu Zhuoxuan. (2013). Platform Strategy: The Business Model revolution sweeping the world. CITIC Publishing House.

[22] Hui-wen Chen. Research on Value Creation based on "Social + E-commerce" Business Model: A Case study of "PDD". (Doctoral dissertation, Harbin University of Commerce). 